\title{
A personal view of how ruminant animals control their intake and choice of food: minimal total discomfort
}

\author{
J. Michael Forbes \\ Institute of Integrative and Comparative Biology, Faculty of Biological Sciences, University of Leeds, Leeds LS2 9JT, UK
}

\begin{abstract}
Voluntary food intake and the selection between foods are important subjects especially in ruminants in view of the economic importance of this class of animal and the complex digestive system with its attendant metabolic peculiarities. There is evidence that intake is limited by the capacity of the rumen as well as by metabolic factors; some theories assume that intake is controlled by the first limiting factor but this is not satisfying on physiological grounds and there is evidence that signals from feedback factors are integrated in an additive manner. It is now well established from research in which animals are given the chance to learn the metabolic consequences of eating food with a particular sensory profile, including a choice of foods, that animals including ruminants can adjust their diet, both quantitatively and qualitatively, to their nutrient requirements. It is proposed that they do this in order to minimise the total of the discomfort generated by the several signals from various body systems. The learning process is aided by the considerable day-to-day variation often seen in the intake of individual animals. An optimisation model is proposed and presented in a simple form, involving the addition of discomforts (calculated as the square of the deviation of the supply of metabolisable energy, crude protein and neutral-detergent fibre) and iterative elucidation of the intake at which total discomfort is minimal. With parameters appropriate for growing lambs the model provides reasonable agreement with observations, both in terms of daily intake and selection between foods of different protein contents. Manipulation of food composition and of nutrient requirements produces predictions broadly in agreement with reality except that protein deficiency has less severe consequences for the model than for real animals; it is proposed that protein deficiency be given more weighting than protein excess, and this may be true for other resources as well. This model is proposed as a philosophy and a starting point for further development and is not purveyed as a complete, working model. It nevertheless provides support for the concept of total minimal discomfort as a suitable base from which to view the control of intake and selection in all animals.
\end{abstract}

Voluntary food intake: Diet selection: Models: Ruminants: Minimal total discomfort

\section{Introduction}

The invitation by the editors of Nutrition Research Reviews to review this subject gives me the opportunity to present a personal view of the control of food intake and diet selection in ruminant animals, how this has developed over the last 40 years or so, and to develop and explain in more detail than previously the minimum total discomfort theory.

Despite many decades of research there is still no unified theory of how animals control their intake of, and selection between, foods with different nutritional characteristics in relation to their physiological state. Ruminant animals are of particular interest because of their economic and ecological importance and their anatomical and physiological adaptations to herbivory. The way in which they control their food intake has been thought to be different from other animals and, despite a great deal of attention, the ways in which the mechanisms of the control of food intake and selection are integrated are poorly understood. A solution to this is of relevance to the drive to make better use of forages and by-products by ruminants to permit sustainability while meeting the food demands of the 10 billion world human population predicted to be reached by 2020 .

Early theories of intake control for animals in general were based on an individual factor and in turn those based on stomach distension, plasma glucose concentration, body temperature, plasma amino acid concentrations or the

\footnotetext{
Abbreviations: CP, crude protein; DE, digestible energy; ME, metabolisable energy; NDF, neutral-detergent fibre; VFA, volatile fatty acid. Corresponding author: Professor J. M. Forbes, fax +44 113 3433144, email j.m.forbes@leeds.ac.uk
} 
presumed hedonic properties of the foods each became popular ${ }^{1}$. Theories for ruminants concentrated on the many experimental observations that intake showed negative relationships with the content of indigestible fibre in the food, and thus on the concept of a physical limitation of intake ${ }^{2}$.

In the 1970s integration of more than one feedback factor was attempted for non-ruminants (quantitatively, Booth et $a .^{3}$; qualitatively, Wirtshafter \& Davis $\left.{ }^{4}\right)$. Meanwhile, primitive models for ruminants were produced which used the proposition that the first of two limiting factors (physical limitation and energetic control) determined daily intake ${ }^{5,6}$ and feeding behaviour ${ }^{7}$. More elaborate approaches added more potential controlling factors but still used the first limiting factor to predict food intake ${ }^{8}$. Fisher ${ }^{9}$ used a mathematical formulation that included more than one factor (protein and fibre in the rumen, and chemostatic feedbacks) simultaneously in calculating daily intake. Combination of the distension and chemostatic feedbacks was by multiplication, with the chemostatic effect being modulated by distension as an exponent to limit the chemostatic effect in relation to distension with, in turn, an exponent to increase the chemostatic effect at high levels of distension. Two fitting parameters (weightings) were used that came from 'previous modelling results'. As discussed later, the use of multiplication and exponentials seems unnecessary and unphysiological, compared with addition of feedback signals.

For any model of food intake to be fully credible it should be able to cope with situations in which two, or more, foods are on offer at the same time, i.e. free choice and supplementary feeding, as well as where only one food is available. The desire to cope with these situations was a major impetus to the new modelling approach detailed later in the present paper.

\section{Characteristics of ruminants}

First, some relevant features of the ruminant and its diet: unlike the horse and its relatives, which cope with the fibrosity of their predominantly grass diet by eating it in large amounts and passing it through the digestive tract quickly, ruminants have evolved mechanisms for retaining food in the body in order to allow time for extensive digestion, by a combination of symbiotic microbes and their own digestive secretions. This delay in passage of digesta is achieved mainly by the development of: a capacious blind sac between the oesophagus and true stomach, the reticulorumen (referred to henceforth as simply the rumen) which harbours symbiotic micro-organisms; by the reticuloomasal orifice, a valve for the regulation of outflow from the reticulo-rumen to the omasum and abomasum; a long small intestine; a relatively capacious large intestine. In addition, breakdown of fibrous material is assisted by rumination, i.e. the regurgitation and remastication of fibrous material from the reticulo-rumen.

The fact that food stays in the rumen for many hours of exposure to microbial fermentation before the animal's own digestive secretions can have any influence means that the absorbed products of fermentation outweigh the absorbed products of mammalian digestion in terms of nutrient supply to the body. Therefore, metabolic adaptations have evolved in parallel with the anatomical adaptations to the herbivorous way of life. The major products of fermentation in the rumen are volatile fatty acids (VFA), predominantly acetate, propionate and butyrate, which are absorbed directly from the rumen. As acetate is absorbed, some is used as a source of energy for activity of the rumen wall and the rest is available for fat synthesis in adipose tissue and mammary gland. Propionate is taken up almost completely by the liver where it is used for glucose synthesis (the ruminant would otherwise be very deficient in glucose, which is required for lactose synthesis and for the brain). Butyrate is mainly used by the rumen wall.

The part of the protein in the diet that is susceptible to fermentation is metabolised by the rumen microbes to ammonia, from which they synthesise their amino acids and proteins; ammonia is also absorbed, converted to urea in the liver, and excreted in urine or secreted in saliva, the latter being an efficient method of conserving $\mathrm{N}$ for subsequent use by the rumen microbes. A proportion of dietary protein escapes fermentation in the rumen and is available for conventional mammalian digestion further along the digestive tract. The fraction of dietary protein escaping fermentation in the rumen depends both on the chemical and physical protection afforded by other dietary constituents and also by the time the digesta spends in the rumen, in turn influenced by the level of food intake and the composition of the diet.

\section{Individual factors affecting food intake}

\section{Physical aspects of intake control}

Long experience of feeding forages to cattle, sheep and other ruminants showed positive relationships between the rate and extent of digestion and the level of voluntary food intake, and there were many other pieces of circumstantial evidence ${ }^{10}$ that were consistent with physical limitations on intake. Displacement of rumen contents with a balloon reduces intake of forage and provides more concrete evidence for the concept of physical limitation of intake that has been widely if uncritically accepted by most for many decades.

Ruminants decrease their intake with dilution of the diet, either naturally with higher fibre content (for example, Blaxter \& Wilson ${ }^{11}$ ) or artificially with such diluents as kaolin (for example, Dinius \& Baumgardt ${ }^{12}$ ), in accordance with a physical limitation theory of intake control. On the other hand, rats, pigs and chickens increase their DM intake in response to dilution of the nutrient content of the food with indigestible material, consistent with metabolic control. However, attention was focused on forage feeds for ruminants and the possible involvement of metabolic factors was, at that time, largely ignored. Despite the general feeling at the time that intake of forages was controlled physically, note that those who gave the subject proper thought '... doubted whether the generalisation would apply throughout the whole range of diet concentrations ...,2 and stated that 'In ruminants there is thus evidence for two types of regulatory mechanism (physical and metabolic) which together determine food intake ${ }^{13}$. 
The concept that ruminants eat that amount of food that provides metabolisable energy for their needs, unless physical limitation intervened, was championed by Baumgardt ${ }^{14}$, who collated results from fifteen experiments with cattle and sheep; plots of these data ${ }^{15}$ demonstrate general increases in intake of digestible energy (DE) for diets with DE content of up to about $12 \mathrm{MJ} / \mathrm{kg}$ and then tendencies to decline with higher DE concentrations. The principles of physical limitation and metabolic control were becoming widely adopted as a framework on which to base our understanding of the control of feed intake in ruminants (for example, Forbes ${ }^{6}$ ). It will be noted that intake per unit live weight $\mathrm{t}^{0.67}$ is higher, at any given feed DE concentration, for lactating cows than for growing cattle or for nonlactating sheep. This agrees with the principle that intake is related to requirements, even in the 'physical' phase of control, but there is still a very large amount of variation in intake unaccounted for by feed DE content or animal type.

\section{Metabolic factors}

Since the early $1960 \mathrm{~s}$, therefore, there has been general recognition that nutrient demand plays a part in the control of intake of low-fibre diets. The mechanisms have been thought to involve the VFA, which are produced in such great quantities by rumen fermentation. Some authors have claimed that the so-called physical limitation of food intake by ruminants is an artifact and that, in fact, the inefficiency or metabolic imbalance experienced by animals given forage diets is responsible for the positive relationship between forage quality and daily intake ${ }^{16,17}$.

Volatile fatty acids. Major candidates as negative feedback factors are the VFA, which fit the criteria for such a control, being produced as a consequence of feeding (more or less in proportion to the amount of food eaten) and having receptors in appropriate places with signals being relayed to appropriate centres in the central nervous system (CNS) (dorsal vagal nucleus in the medulla oblongata). VFA infused into the rumen consistently depressed intake while those given intravenously did not ${ }^{18}$ and chemoreceptors in the rumen wall sensitive to VFA have been demonstrated ${ }^{19}$. However, most experiments involving infusions of VFA into the rumen have used the $\mathrm{Na}$ salts of the VFA, thereby increasing the osmolality of digesta in the rumen. Carter \& Grovum $^{20}$ showed that sodium chloride and other osmotically active solutions, when infused into the rumen, had a marked depressing effect on intake, the receptors for which were deduced to be in the wall of the rumen. Were the effects of $\mathrm{Na}$ salts of VFA also due to the increase in osmolality of rumen fluid? Two lines of evidence show that VFA have an intake-depressing effect, additional to any effects of their salts via osmotic mechanisms. On the one hand, intraruminal infusion of sodium acetate solutions depresses intake more than equimolar amounts of sodium chloride both in sheep ${ }^{21}$ and in cows ${ }^{22}$. On the other hand, the effects of salt infusions into the rumen on feed intake are very much less when access to water is allowed, compared with when water is withheld ${ }^{23,24}$, and it is to be noted that Carter \& Grovum ${ }^{20}$ deprived their sheep of water during the infusion periods, thereby exacerbating the effects of the salts. It is deduced that the osmolality of rumen contents might be one factor influencing feed intake, but is not of over-riding importance.

Whereas acetate appears to exert its effects at the level of the rumen, propionate, the second in importance quantitatively, has an effect via the liver ${ }^{25}$. The liver is probably sensitive to anything that increases its rate of oxidation of substrates and thus is likely to be of great importance in the control of feed intake in ruminants, as it is in simplestomached animals ${ }^{26}$.

Protein and other nutrients. Feed intake is also influenced by the products of protein digestion and $\mathrm{N}$ metabolism. Feeds high in protein or non-protein $\mathrm{N}$ lead to excessive production of ammonia, high blood ammonia concentrations and toxicity, which the animal seeks to avoid by reducing its intake of feed. Low-protein feeds, on the other hand, rather than being eaten in increased quantities as might be expected, also suffer from low intakes. If the animal increases its feed intake in order to try to maintain an adequate intake of protein, then it suffers an excess of other nutrients and it has to balance the problems arising from insufficient amino acids with those arising from excess energy. In reality the interference with metabolism from inadequate protein intake and amino acid imbalance invariably results in low intakes of low-protein feeds.

Toxic excess of a mineral, vitamin or individual amino acid causes illness, which the animal avoids by reducing its daily intake, even though this reduces its supply of energy and protein ${ }^{27}$. Deficiency of an essential nutrient disrupts metabolism and depresses food intake, presumably because animals feel more comfortable if they eat less food and so accumulate a lesser amount of metabolites than if they continued to eat at the same rate as before.

\section{Models of intake in ruminants}

Models can be helpful in providing a framework whereby combinations of simple relationships and ideas can be put together and used to test hypotheses and to suggest new experimental approaches. There is additionally the impetus to provide methods of predicting food intake and selection by farm animals in order to provide management tools to optimise output, for example, milk yield, in relation to costs, the major one being the cost of food.

\section{First limiting factor models}

The concept used in the models of Forbes ${ }^{5,6}$, that intake is limited either by physical or metabolic constraints, has subsequently been taken and developed into a dairy-cow model intended for practical use ${ }^{28}$. To this end, readily available measurements including live weight, fatness at calving and milk production potential of the cow, and digestibility and DM content of the food, with a genetically driven mobilisation of body lipid which limits the rate of increase in intake after calving have been incorporated. The predictions are sufficiently robust for the model to be made available to advisory organisations for use in the field, but its assumption of a fixed physical limit to forage intake is not realistic in the view of this author and provided a major 
incentive to develop other approaches that are more physiologically satisfactory (see later).

The model for food intake by growing cattle proposed by Poppi et al. ${ }^{8}$ is another example of the 'constraints' type. In this model the intake for each limiting factor is calculated and the lowest of these is taken as the predicted intake. Six factors are used:

(1) Genetic limit to protein deposition. This is set at a fixed rate and the amount of dietary protein required to support this growth is calculated from the efficiencies of digestion and utilisation of dietary protein.

(2) Environmental limit to heat dissipation. This is fixed at a given rate from knowledge of the animal's maximal rate of heat loss in relation to environmental conditions.

(3) ATP degradation is speculatively included on the basis that inefficient metabolism, for example in protein deficiency, causes ATP accumulation. This is calculated according to the balance of resources provided by the food and the requirements of the animal.

(4) Rate of eating, on the basis that ruminants are unwilling to spend more than $12 \mathrm{~h} / \mathrm{d}$ eating.

(5) Faecal DM output, on the basis that there is a physical limit to the amount of fibre that can be handled by the digestive tract.

(6) Rumen fill, on the basis that capacity of the rumen and rates of degradation and absorption of food are limiting for many forages.

The strengths of this approach are that it includes more factors than other models and encompasses dietary imbalance by means of ATP degradation. However, a major weakness is that the factors are used in a 'first limiting factor' manner rather than being integrated; each limiting factor is considered to have no effect on intake until the limit is reached and from that point on to allow no further intake. It seems to this author to be untenable that stimulation of receptors sensing rumen fill, for example, should contribute nothing to intake control until a certain degree of stretch is reached, at which point rumen fill suddenly becomes the only factor to control food intake! In fairness to Poppi et al. ${ }^{8}$ they do point out that more than one factor may under some circumstances lead to similar prediction of intake and that there is some greyness in deciding exactly which of more than one factor is controlling intake.

\section{Optimisation models}

Optimisation is the process of obtaining the best compromise between benefits and costs. The proposition that animals optimise energy gathering is a cornerstone of much recent ecological theory and the book of Stephens \& $\mathrm{Krebs}^{29}$ is much-quoted in this respect. It is worth noting that optimisation is in fact a form of maximisation, but it is just that the parameter being maximised can be subdivided into meaningful components, for example, fitness is maximised by optimising the balance between survival and reproduction. Optimisation can then be considered as a maximisation of the sum of the benefits or a minimisation of the sum of the costs and this helps to rationalise the difference between the models that involve genetic potential v. constraints and the 'optimisation' models. The potential $v$. constraints model usually implies that it is always worth attaining potential regardless of the size of the deviation from potential whilst optimisation, and the minimal total discomfort model set out later, assumes a variable slope to the worth $v$. deviation function.

Thornley et al..$^{30}$ present a cost-benefit model of sheep grazing a grass and clover pasture and use energy as the currency, but did not include protein or any other resource. Preference is generated from the relative rates with which animals can harvest of grass and clover, the costs of foraging and the yields of net energy from the two species of plant. The increased search time accompanying a more selective diet acts as a 'discomfort', reducing the likelihood of the animal making the perfect selection. (The term discomfort is used advisedly as it implies less of a conscious process than 'malcontentment' or 'unhappiness'. Rather than talking about 'increased discomfort' we could say 'reduced comfort' but they mean much the same thing and there are some practical advantages in using 'discomfort' rather than 'comfort' in this presentation as the target for minimum discomfort is, presumably, zero and therefore quantifiable, while for comfort it would be infinity and therefore unquantifiable!)

The hypothesis of Ketelaars \& Tolkamp ${ }^{16,31}$ is a further example of an optimisation approach. They proposed that ruminants adopt that level of food intake (including forages) which allows maximum efficiency of utilisation of $\mathrm{O}_{2}$ consumption for net energy provision (energy used for 'production' plus the fasting heat production) and that physical limitation of intake is an erroneous concept based on inappropriate experimental methods and interpretation. They quantified their idea using statistical relationships obtained from data on growing sheep and cattle in calorimeters collected from the literature ${ }^{32}$. The hypothesis has been criticised by Emmans \& Kyriazakis ${ }^{33}$ on three main grounds: (a) the form of the relationship between energy supply and energy retention used in by the Agricultural Research Council ${ }^{32}$ was inappropriate; (b) the theory does not predict the well-known changes in intake with age; (c) very large changes in intake were needed to produce small changes in the predicted efficiency, rendering the model very insensitive. The following pertinent questions are not addressed by Tolkamp \& Ketelaars $^{16}$ other than to suggest that intracellular $\mathrm{pH}$ might be the integrating signal:

(a) how is net energy measured when it is not a physiological reality but rather a convenient concept invented by scientists?

(b) how is $\mathrm{O}_{2}$ consumption measured when it occurs in all tissues, even those not thought to be capable of neural or endocrine transmission of information?

(c) how is the ratio between the two calculated?

Pittroff \& Kothmann ${ }^{17}$ have also argued against previous hypotheses involving a component of physical control, but their proposed alternative is not expressed in a testable manner. These authors have subsequently criticised many models of ruminant food intake on the grounds of unsoundness of the mathematical and/or biological concepts applied and the inadequate documentation provided to 
facilitate a thorough assessment of their logic and mathematical relationships; serious attempts at sensitivity analysis or proper validation have rarely been made ${ }^{34}$. They proceed to review many published prediction models for sheep and cattle and this author agrees with their strong criticism of the lack of a formal approach to modelling in most of the cases cited.

The debate can be seen as being between those, on the one hand, who propose that animals seek to meet their genetic potential but may be prevented from doing so by limiting factors in the food or the environment, and those who contend that intake results from an optimisation of costs and benefits, on the other. To some extent the differences may be semantic but they nevertheless have a strong influence on the way in which modelling is approached. We will return to quantitative hypotheses after dealing with other topics germane to the final thesis.

\section{Selection from a choice of foods}

While the study of food choice has often been seen as a sequel to the study of intake of a single food, the former is normal in wild ruminants and in the ancestors of domesticated animals. Therefore, the control of intake of a single food should be seen as a special case of the more general situation in which an animal has two or more food materials available. It had been thought that the presence of the rumen might prevent ruminants from being able to learn to associate the sensory properties of foods with the metabolic consequences of eating those foods, a necessary prerequisite for effective diet selection. However, considerable amounts of evidence have been accumulated to show that cattle, sheep, goats and deer can manage their nutrition effectively by making appropriate choices. It is not intended to go into details in the present paper, but the reader is referred to the book of Forbes ${ }^{27}$ and the review of Forbes \& Provenza $^{35}$ for examples and discussion.

Changes in the composition of one or both of a pair of foods on offer results in changes in the proportions selected in the direction expected in order that a balanced diet continues (for example, Tolkamp et al. ${ }^{36}$ ). In the example in question, it took dairy cows about $3 \mathrm{~d}$ to adjust their preferences to a new, stable level after the addition of urea to, or its removal from, both of two mixed feeds with different crude protein (CP) contents. Yet the compensation did not result in a constant intake of protein, or of urea, and we might question the animal's ability to regulate their nutrient intake by appropriate choice between foods. Care in interpretation is required, however, and where the proportion of two foods eaten does not provide a 'balanced' diet we should question whether we or the cow are the better judge of what the animal feels to be in its best metabolic interests.

In a more subtle test of cows' ability to select wisely, Lawson et al. ${ }^{37}$ offered silage ad libitum, together with a total $6 \mathrm{~kg}$ concentrate supplement per d, which they could take from foods high or low in digestible undegraded protein. Initially there was considerable variation in the proportions selected but gradually, over a period of about $10 \mathrm{~d}$, they settled down to a high protein:total food ratio which was different between different cows, but was significantly correlated with their pre-treatment milk protein output, i.e. they seemed to be controlling their protein intake to meet their 'requirements'.

In both of these cases it seems that the cows needed a few days in which to learn the new associations between the taste and other sensory properties of the foods and how they felt metabolically after eating these foods. Separation of the former and the latter is possible; for example, by infusing a nutrient into the digestive tract at the same time as offering a food with a characteristic flavour, sheep can be taught to prefer or avoid this food in future, depending on the dose of nutrient infused ${ }^{38}$ (see later). Such experiments demonstrate the futility of using the word 'palatability' unless the history of the animal in question in relation to the food(s) under consideration is known.

\section{Components of a new approach to modelling food intake}

Food acceptability in relation to 'nutrient' requirements; the necessity for learning

Raubenheimer \& Simpson ${ }^{39}$ propose that animals are increasingly attracted to a food and eat it as the concentration of the nutrient (more correctly, food resource) in question increases from zero to the optimum, i.e. there is an increasing preference for a more balanced diet. This attraction then falls as the concentration of the resource rises further, eventually reaching even lower levels than that of the nutrient-free food, i.e. there is aversion due to the toxic nature of an excess of the nutrient. For ruminants, Forbes \& Provenza $^{35}$ have detailed the evidence for preference for, or aversion to, a food being proportional to the deviation of supply of a nutrient from optimum and developed the concept of metabolic discomfort. As stated earlier, it had been thought that, unlike simple-stomached animals, ruminants might not be able to make associations between the taste, smell, colour or position of a food and subsequent metabolic effects in view of the mixing and storage of meals in the rumen, making it difficult for the animal to know which food had caused any feelings of malaise. It is now known, however, that ruminants can indeed learn such associations. Lithium chloride $(\mathrm{LiCl})$ has been widely used to induce malaise in a wide range of animals and it has been shown that sheep develop a conditioned taste aversion to a novel food given after injection with an appropriate dose of $\mathrm{LiCl}^{40}$, the strength of which is proportional to the dose administered. Reluctance to eat novel food (neophobia) also increases as a function of the $\mathrm{LiCl}$ dose associated with the last novel food encountered.

Normal constituents of the diet can also induce preferences and aversions, depending on the concentration of the resource in the diet and the animal's requirement for that resource. When sheep were given a novel flavoured food after receiving different doses of casein into the rumen they developed either preferences or aversions, depending on the dose of casein administered ${ }^{38}$ (Fig. 1). The basal diet was calculated to provide insufficient protein $(\mathrm{N} \times 6.25)$ and the small amounts of casein ( 9 or $18 \mathrm{~g}$ ) given to alleviate the deficiency-induced preferences for the flavours associated with their administration. With higher doses ( 35 and $53 \mathrm{~g}$ ), however, aversions were conditioned, as presumably these 


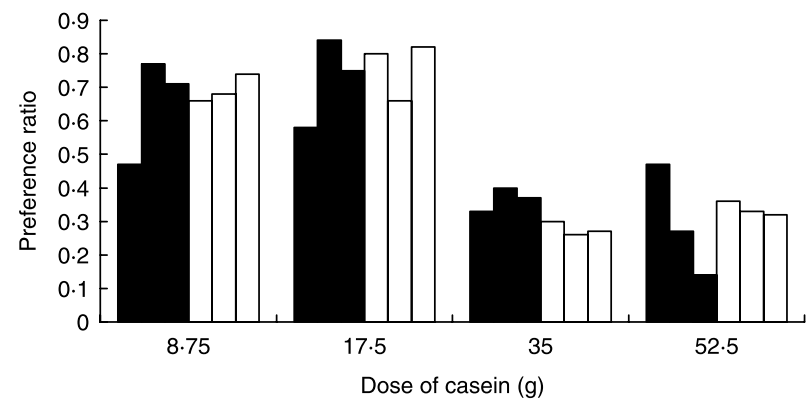

Fig. 1. Preference for flavour associated with administration of four doses of casein into the rumen in the first, second and third tests during conditioning $(\square)$ and 7,21 and 35 d post-conditioning $(\square)^{38}$.

larger amounts provided toxic overdoses that the sheep would prefer to avoid. These preferences and aversions persisted for at least $35 \mathrm{~d}$ post-conditioning. Thus there is a graded response to different amounts of the same material, with preference for small amounts that alleviate a deficiency but aversion to large amounts that are toxic. Animals behave in a manner that would optimise their nutritional balance and this gives support for a continuum of flavour preferences and aversions created by different amounts of the same nutrient source. The concentration of the nutrient at which preference turns to aversion will depend on the rate at which the animal is utilising that nutrient, i.e. its nutrient requirements, which themselves are dependent on its physiological state and environmental conditions.

When Villalba \& Provenza ${ }^{41}$ administered low levels of acetate or propionate into the rumen of sheep fed a diet limiting in energy they induced a preference for the flavour paired with the infusion. However, with higher doses, a flavour aversion was induced, again suggesting a role for learning about different concentrations of metabolites in the control of diet selection. Such learning occurs despite the fact that animals can manage quite well on an imbalanced diet by metabolising excess nutrients. However, mismatches between supply and demand for particular nutrients generate disadvantages such as increased heat production and elevated blood levels of toxic materials, which animals would rather avoid if they can, i.e. the imbalances induce discomfort. There is clearly a need for animals to learn to associate properties of a food that they can recognise before ingesting the food, with the internal effects experienced after eating that food, so that they can avoid eating harmful foods (or at least limit their intake of harmful foods).

\section{Additivity of stimuli affecting intake}

Evolution has provided animals with receptors of various types in order to inform the CNS of physical or metabolic events in peripheral organs and tissues. Forbes \& Barrio ${ }^{42}$ have summarised the neural pathways in ruminant animals and it can be deduced that the relationship between stimulus (for example, stretch of the digestive tract, extent of oxidation in the liver, blood concentration of leptin) and reduction in intake is continuous ${ }^{43}$ and not a step function.
Thus far we have dealt with a number of theories as if each factor (fill, metabolic signals, efficiency of $\mathrm{O}_{2}$ utilisation) was independent of the others, if not mutually exclusive, and the point has been made earlier that this is physiologically unlikely. It has been proposed, therefore, that the various signals reaching the CNS are integrated in an additive manner ${ }^{43,44}$ and the current proposal is that any discomforts generated by under- or over-supply of nutrients, or by other factors such as social and climatic, are additive. Administering more than one treatment (balloon inflation, acetate infusion, propionate infusion) has additive effects on the intake of compound food by male sheep ${ }^{45}$ and of grass silage by dairy cows ${ }^{46}$. The large degree of convergence in the autonomic nervous system also strongly suggests additivity as an appropriate method for combining afferent signals in the $\mathrm{CNS}^{43}$ and it has been elegantly demonstrated by Jessen ${ }^{47}$ that central and peripheral temperature signals in the goat are integrated in an additive manner in the control of heat production. Not only are receptors in the rumen wall sensitive to both mechanical and chemical stimulation ('polymodal'), but also the same stimulus affects receptors in different parts of the viscera ('polytopic'). Stimulation of one visceral site modifies the effects of the same type of stimulus at another site and integration also occurs in the CNS, whereby the effects of visceral stimulation might be integrated with signals from other stimuli (for example, the special senses). A theoretical reason for combining signals by addition rather than by multiplication is that the latter leads to an integrated signal of zero when one signal is zero (for example, with a non-bulky diet), when clearly there is still controlling information coming from the other families of receptor $^{48}$.

Thus the many small increases in the strength of signals from gut receptors during and following a meal, insufficient independently to be satiating, might be of adequate strength when added together - intake might be controlled by the sum of many small signals and not exclusively by a major change in one signal. This would explain why an experimental treatment with a single factor has to be applied at very high levels in order to stop feeding, or even to depress intake significantly ${ }^{49}$.

On this basis it is possible to reinterpret observations that were paradoxical, according to previous theories. For example, a lactating cow offered a forage can have a higher feed intake and a greater degree of rumen fill than a nonlactating $\operatorname{cow}^{50}$ and this had been ascribed to a mysterious effect of nutrient demand on the sensitivity of mechanoreceptors in the rumen. Similarly, alleviation of protein deficiency in sheep led to an increased volume of rumen contents, which Egan $^{51}$ ascribed to a resetting of the sensitivity of rumen tension receptors according to the degree of nutritional deprivation. If, as proposed earlier, negative feedback signals are added by the CNS then we can speculate that the lactating cow (or the growing sheep on a balanced diet) can accommodate a greater degree of distension before the total signal from visceral organs becomes satiating because her rate of utilising nutrients is higher than those of a non-lactating cow (or sheep on an imbalanced diet) and there will be less negative feedback from chemoreceptors. 


\section{Variability and the updating of metabolic information}

It will be proposed later that animals learn to eat that amount of food that provides minimum discomfort. If that is true then individuals need to change their intakes from time to time in order to find out whether the amount they are eating is still optimal. In particular, when a food with novel sensory properties is offered the animal starts at a low level of intake (neophobia) and then 'experiments' by gradually increasing its intake until it exceeds the point of minimum discomfort; it then returns to the point of minimum discomfort and stabilises at that point (see example from J Hills in Forbes \& Provenza ${ }^{35}$ ). Unless the animal takes some further action it will stay at this level of intake and might miss out on potential improvements in its comfort status that might be achievable by adapting intake to changes in time in its nutrient 'requirements' and/or nutrient yields of the food(s). The animal could continue to experiment by varying its intake slightly day by day and many datasets show significant day-to-day variation within individual animals. Whether or not this variability is purposeful, its effect is to update the animal on its relationship with its food and to allow it to reassess its comfort levels and, if necessary, adopt a new mean daily intake.

The importance of variation in intake in assisting learning is illustrated by the results of Villalba \& Provenza ${ }^{52}$. They observed that sheep that were given a fixed amount of $\mathrm{LiCl}$, irrespective of how much of a novel food they ate, did not generate a learned aversion to that food. However, when the dose of $\mathrm{LiCl}$ was proportional to the weight of novel food eaten then a conditioned aversion developed. It appears that the animal 'knows' how much food it has eaten and relates that to how much discomfort is subsequently felt.

Provenza $^{53}$ has proposed that there is a decrease in preference for food just eaten as a result of a combination of sensory input (flavour, colour) and postingestive effects (nutrients, toxins) unique to each food. Foods providing toxins, nutrient deficiencies or high levels of rapidly digestible nutrients generate stronger aversions than milder foods. Because satiety and surfeit represent points along a continuum, aversions occur even when a food is balanced for nutrients. Eating any food too frequently or in excess is likely to generate an aversion, followed by a preference as hunger increases, and variation in food intake, as well as food choice, is engendered.

\section{Characterisation of day-to-day variation in intake by dairy cows}

Some examples of individual daily variation in the intakes of grass silage by cattle are given by Forbes ${ }^{54,55}$ and a further example is now presented. Fig. 1 shows the daily intakes of grass silage by a lactating dairy cow over an $89 \mathrm{~d}$ period (from the data of Lawson et al. ${ }^{37}$ ). From the raw data it can be seen that there are considerable variations, both day by day and over the whole period of observation. The latter are likely to be due to stage of lactation and environmental effects and are shown by the smoothed line in Fig. 2. Subtracting the smoothed from the raw data provides the 'rough' data whose average is zero but whose fluctuations

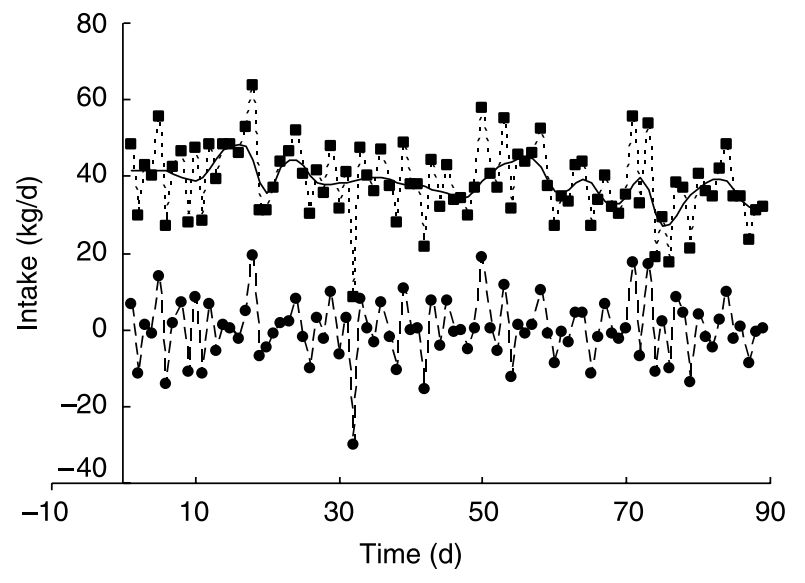

Fig. 2. Observed $(\square)$, smoothed $(-)$ and 'rough' $(\bullet)$ daily intakes of silage by cow 541 over an 89 d period (from data of Lawson et al. ${ }^{37}$ ).

clearly show the daily variations of the type present in most sets from individual animals fed ad libitum.

Because the rough data are 'saw-toothed', i.e. showing apparently regular fluctuations above and below the mean, it was postulated that over a period of a few days there is compensation - a high intake on one day is followed by low intake the following day or few days. To explore this, the rough data for cows (including those shown in Fig. 2) on silage-based diets were subject to autocorrelation analysis whereby the relationships between intakes on each day and each of the next $6 \mathrm{~d}$ were examined. Although intake was significantly negatively related to intake on the following day in each animal, and in some cases to intakes 2 or $3 \mathrm{~d}$ later, this is a characteristic of a simple smoothing process as randomly generated data, smoothed in the same way, also produce significant negative correlations between each day's intake and intake on the following day! This suggests that the day-by-day variation in intake by cows (and beef cattle, sheep, pigs and chickens that we have analysed) is random, but yet intake is clearly controlled over this timescale as compensation for dietary changes occurs within a few days. While not claiming that these short-term fluctuations in intake are programmed with the purpose of assisting the animals to achieve a suitable balance between intake and requirements, they will nevertheless help in this direction.

A similar situation is also seen in diet selection by ruminants, where large short-term fluctuations are underlain by long-term stability ${ }^{56}$ and this leads to the conclusion that over a period of days animals regulate their intake and selection of food by a process involving correction of shortterm errors. However, neither the mechanisms nor the statistical characteristics of such phenomena have yet been resolved, providing a challenge for the future.

\section{Integratory theories}

It is clear that feeding and food choice are influenced by a multitude of factors. Models that encompass too few of these, or only one of them, are not likely to be able to behave realistically while those that try to incorporate many or all of 
the factors run the risk of being unstable and will almost certainly lack sufficient data to characterise quantitatively some of the factors. Selection of the minimum number of factors consistent with the aims of the model is therefore necessary and, as far as food is concerned, their content of energy and protein might be considered minimum requirements, alongside the target animal's 'requirements' for energy and protein. The concept of requirements, although widely invoked, is a difficult one to sustain when it is the nature of the animal's responses to a range of nutrient quantities and qualities that should underlie the modelling approach. In other words, animals will survive moderately imbalanced diets, but with altered (and less efficient) function. However, we can imagine a diet which contains that mixture of available nutrients which can be dealt with by the animal with minimum metabolic effort to provide for its genetically programmed physiological needs. This, eaten in the right amounts, would be a 'balanced' diet which would provide for the animal's 'requirements'.

Raubenheimer \& Simpson ${ }^{39}$ imagine foods as linear trajectories from the origin of a graph of the weight eaten of one resource against the weight eaten of another resource, the number of dimensions equalling the number of resources included in the model. In this formulation the angle of the trajectory represents the resource content of the food and the distance moved along it represents the animal's intake of that resource (see Figs. 1 and 2 of Raubenheimer \& Simpson ${ }^{39}$ ). Thus, an animal's requirements at any given time can be represented by a point in the multidimensional space representing the animal-food interactions. If the animal's current state is not at the 'ideal' point, then the animal is assumed to move from its current position toward this ideal. The model to be presented later in the present review draws on the concepts presented there.

Raubenheimer \& Simpson ${ }^{39}$ show three hypothetical outcomes of experiments in which animals are fed one of a number of foods differing in the balance of nutrients. These illustrate three alternative rules that animals might follow: (a) the animal eats to maintain constant intake of one nutrient irrespective of food composition; (b) the animal eats to achieve equal errors for each nutrient; (c) the animal eats to minimise error from all nutrients. Fig. 3 shows the food rails and observed intakes of metabolisable energy (ME) and CP by the growing lambs of Kyriazakis \& Oldham ${ }^{57}$ plotted according to Raubenheimer \& Simpson ${ }^{39}$. The points approximate to a segment of a circle; rule (a) is therefore not being followed, unless they are holding constant the intake of some nutrient other than energy or protein in which case we have no basis on which to guess which one it might be; nor do the lambs follow the 'equal error' (b) rule. Rather they seem to favour the 'closest distance' rule (c), i.e. they were attempting to minimise the composite of the mismatches between supply and 'requirement' for energy and protein. Intakes of $\mathrm{ME}$ for lambs in the various dietary treatments ranged from $18-22 \mathrm{MJ} / \mathrm{d}$ while intakes of CP varied between $130-400 \mathrm{~g} / \mathrm{d}$ suggesting a relatively strong defence of energy but with some compensation for protein, i.e. there is a weighting for a proportional error in energy supply that is greater than the weighting for an error in protein supply.

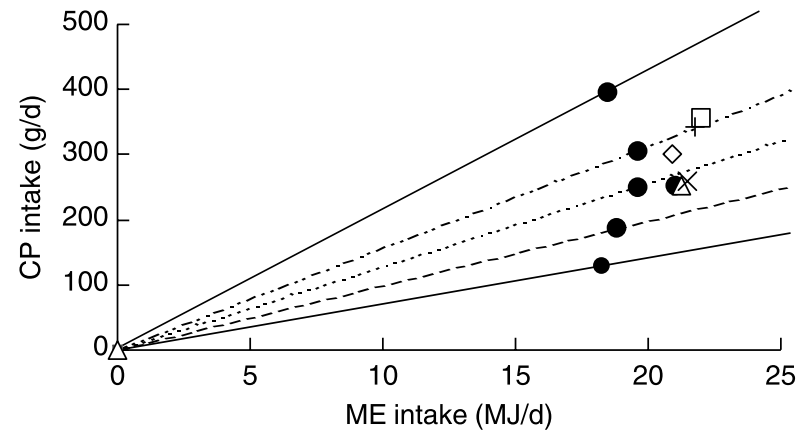

Fig. 3. Intakes of metabolisable energy (ME) and crude protein (CP) by the sheep of Kyriazakis \& Oldham ${ }^{57}$. ( ), Intakes of animals on single feeds with protein contents of 235 (feed $\mathrm{H}$; high-protein), 172 (feed C), 141 (feed B), 109 (feed A) and 78 (feed L; low-protein) g $\mathrm{CP} / \mathrm{kg}$ (top line downwards), the lines representing the 'rails' along which the animals pass as they eat; not attached to a line is the intake of feed $U$, which was feed $L$ plus $21 \mathrm{~g}$ urea/kg, having a $C P(N \times 6 \cdot 25)$ content of $132 \mathrm{~g} / \mathrm{kg}$. Intakes by choice-fed animals: $(\square)$, choice of feed $\mathrm{C}$ and feed $\mathrm{H}(\mathrm{CH}) ;(+)$, choice of feed $\mathrm{U}$ and feed $\mathrm{H}(\mathrm{UH}) ;(\diamond)$, choice of feed $B$ and feed $\mathrm{H}(\mathrm{BH}) ;(\Delta)$, choice of feed $L$ and feed $\mathrm{H}(\mathrm{LH}) ;(\times)$, choice of feed $A$ and feed $H(A H)$.

\section{An exploratory model based on minimal total discomfort}

\section{Propositions}

An approach based on these lines has recently been developed ${ }^{15,35,55,58}$ with the following propositions.

Optimal supply of nutrients. 'Requirements' for nutrients or other constituents of the food (referred to as resources hereafter) are determined, at any point in time, by the genetic potential of the animal and any deviation from this caused by previous malnutrition (in its broadest sense); the 'requirement' for a resource is the rate of supply of the resource from its food that most closely matches the rate at which it is programmed to utilise that resource, i.e. the 'optimal' rate of supply of that resource.

Deficiency or excess. Deficiency or excess of one or more resources will create 'discomfort' related to some function of the magnitude of the deviation from optimum; resources, as well as being nutrients, include such things as time spent eating and distension or other physical stimulation, above certain thresholds.

Transformation of discomforts. Discomforts can be brought into the same units by expressing them as proportions of the optimal supply for each resource (similar to Fisher ${ }^{9}$ ); these discomforts become proportionately more severe the greater the deviation of the current level of the resource from the ideal; this is quantified by squaring the deviation which has the added advantage of allowing deficiencies (negative discomforts) to be added to toxicities or oversupplies (positive discomforts). It seems highly unlikely that the same proportional deviation in supply of several resources will have the same discomforting effect, so that a different function for each resource may well be found to be necessary. 
Summation of discomforts. As suggested earlier on physiological grounds, these squared deviations can then be added together. Further support for addition is as follows. Take as an example the case of the intakes of two food resources, energy and protein, plotted one against the other (Fig. 4). The animal's current food intake provides energy and protein in amounts represented as 'current' ( $\mathrm{cE}$ and $\mathrm{cP}$ respectively) while its optimal intakes of energy and protein are shown as 'optimal' (oE and oP respectively); to get most directly from 'current' to 'optimal' the animal follows the thick arrow from the former to the latter. The proportional deviations in energy supply $(\mathrm{dE})(\mathrm{dE}=(\mathrm{cE}-\mathrm{oE}) / \mathrm{oE})$ and protein supply $(\mathrm{dP})$ $(\mathrm{dP}=(\mathrm{cP}-\mathrm{oP}) / \mathrm{oP})$ give a combined deviation (Pythagoras) of the square root of the sum of $(\mathrm{dE})^{2}$ and $(\mathrm{dP})^{2}$.

More than two food resources are represented by additional dimensions and, in general, total discomfort (the distance from 'current' to 'optimal') is calculated as:

Total discomfort $=\sqrt{\sum_{j=1}^{i} w_{j}\left(\left(o_{j}-c_{j}\right) / o_{j}\right)^{2}}$,

where $w, c$ and $o$ are the weighting, current and optimal supply for resource $j$ out of the set of $i$ resources. All the weightings are set to 1 in this example.

Minimisation of total discomfort. This total discomfort is then minimised by changing intake and/or selection of foods progressively in a direction that reduces total discomfort; an animal prefers to avoid this discomfort and changes its daily intake in order to try to reduce the discomfort, learning to associate the sensory properties of the food(s) with the total discomfort subsequent to eating that food(s). At this stage the 'sensory properties' of foods are not explicit in the model and it is taken for granted that foods are distinguishable by the animals' special senses.

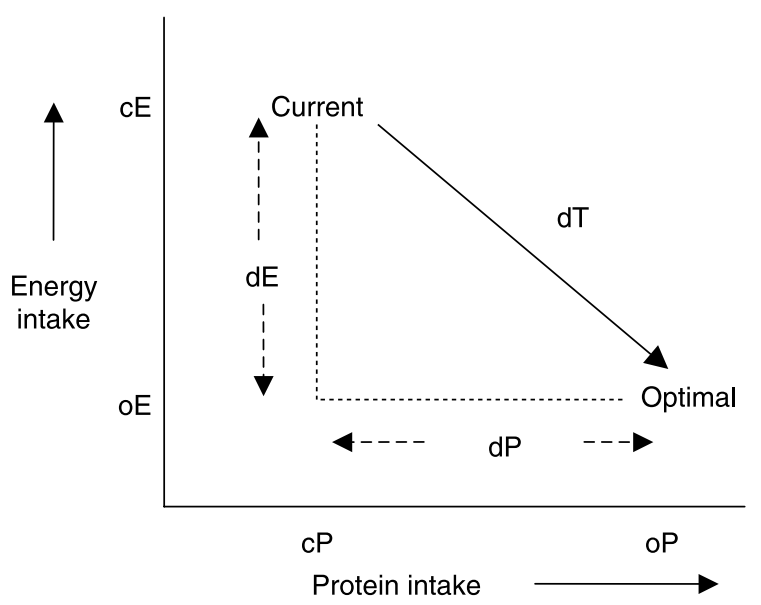

Fig. 4. Connection between current and optimal intakes of energy (E) and protein $(P) . c E$ and $C P$ are the current intakes of $E$ and $P$, respectively and $\mathrm{oE}$ and $\mathrm{oP}$ are the optimal intakes. $\mathrm{dE}$ is the proportional deviation of energy $((\mathrm{oE}-\mathrm{cE}) / \mathrm{oE})$ while $\mathrm{dP}$ is the proportional deviation for protein $((\mathrm{OP}-\mathrm{CP}) / \mathrm{OP})$. Application of Pythagoras's theory allows dT, the overall deviation between the current and optimal positions represented by the diagonal solid arrow, to be calculated as $\sqrt{ }\left(\mathrm{dE}^{2}+\mathrm{dP}^{2}\right)$.

\section{Implementation}

Formally, the model for a single food is:

Intake $=$ minimise $\sqrt{\sum_{j=1}^{i} w_{j}\left(\left(c_{j}-o_{j}\right) / o_{j}\right)^{2}}$,

where $c, i, j, o$ and $w$ are as defined for equation 1 . For an arbitrary starting rate of intake, for each of the $i$ resources being considered, the quantity of the resource provided by this rate of intake is calculated, the requirement for that resource subtracted, the difference expressed as a proportion of the requirement, squared and multiplied by the weighting factor for that resource (if weightings are to be used). The results are summed and the square root taken to calculate the total discomfort. This is repeated with different rates of intake until minimal total discomfort is attained.

Food resources to be considered. For the purposes of the current exercise the three resources to be included initially are: energy, protein and dietary bulk; the 'standard' food used is a typical forage containing $10 \mathrm{MJ} \mathrm{ME} / \mathrm{kg} \mathrm{DM}$, $0 \cdot 12 \mathrm{~kg} \mathrm{CP} / \mathrm{kg}$ and $0.60 \mathrm{~kg}$ neutral-detergent fibre (NDF) $/ \mathrm{kg}$. Available energy is expressed as metabolisable energy (ME; those food entities that yield energy in a manner useful to the animal) and the function of the deviation of supply from requirements is unity, i.e. the same discomfort is generated by the same proportional deviation of supply from requirement, whether this is a deficiency or an excess.

For the purposes of this exercise it is assumed that the foods are balanced for minerals and vitamins.

Likewise, protein $(\mathrm{CP})$ generates discomforts whether in deficiency or excess. NDF, on the other hand, only generates discomfort when in excess of a threshold for bulk in the rumen.

Animal 'requirements'. The quantity of ME that best matches the animal's requirements is, for a rapidly growing lamb of a given kind at a weight of about $35 \mathrm{~kg}$, assumed to be $20 \mathrm{MJ} / \mathrm{d}^{57}$ on the basis that their lambs grew best on diet B which gave an intake of 19.6 MJ ME. Similarly, a 'requirement' of $0.251 \mathrm{~kg} \mathrm{CP} / \mathrm{d}$ is specified and NDF induces discomfort when its intake is greater than $0.35 \mathrm{~kg} / \mathrm{d}$.

Graphical representation. The implementation of the model can conveniently be illustrated graphically. Rather than plotting one resource against another and representing intake by a point in that multidimensional resource space ${ }^{39}$ (Fig. 3), with its inherent difficulties of visual presentation when there are more than two dimensions, discomfort is plotted against intake with as many lines on this graph as there are resources being considered (Fig. 5). When the intake of food supplies exactly that amount of ME the discomfort due to ME is zero; intakes higher or lower than this lead to discomfort which increases with the square of the deviation from the ME required to meet the animal's potential for growth. This relationship is shown in Fig. 5 as a U-shaped curve (squared deviations).

Protein is expressed as CP (in which amino acids are assumed to be present in a balanced mixture). Also shown in Fig. 5 is the curve for $\mathrm{CP}$; the intake of food that provides 


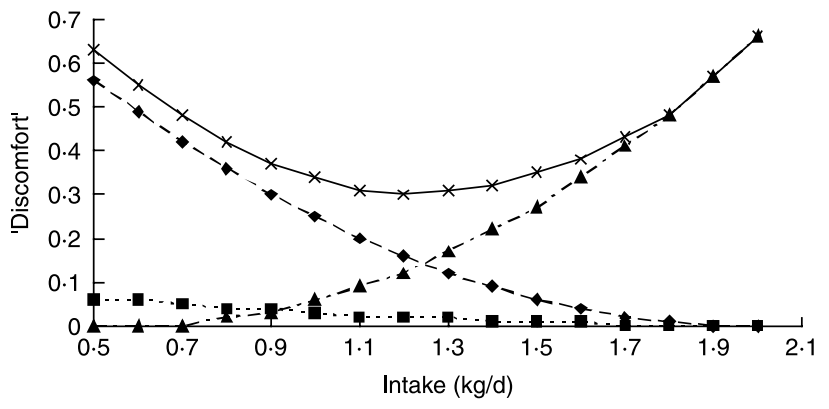

Fig. 5. Proposed discomfort due to metabolisable energy $(\diamond)$, crude protein $(\boldsymbol{\square})$, neutral-detergent fibre $(\boldsymbol{\Lambda})$ and the sum of these $(X)$ against intake of a forage food by growing sheep (for details, see Implementation (Graphical representation) section).

the required amount $(0.25 \mathrm{~kg} / \mathrm{d})^{57}$ is different from the intake that satisfies the ME requirements (the food is imbalanced).

NDF (those physical properties of the diet which generate bulk in the digestive tract) is used as an index of dietary bulk $^{59}$. In this case discomfort is only generated if current supply exceeds optimal supply. NDF represents the physical bulk of the food and it is assumed that there is a threshold of NDF intake below which there is so little stimulation of stretch receptors that it does not contribute to discomfort and therefore has no effect on intake. Above this threshold of $0.35 \mathrm{~kg} / \mathrm{d}$ in the present example, there is progressive discomfort, again related to the square of the deviation from the weight of NDF eaten daily and the NDF intake above which discomfort is generated (Fig. 5).

For each level of food intake tested, the various discomfort signals are added to generate the total discomfort level. In Fig. 5 the sum of the discomforts at various rates of food intake is shown as a heavy solid line, which is at a minimum level for an intake of $1.2 \mathrm{~kg} / \mathrm{d}$, i.e. the level of intake that is predicted to be eaten by the animal whose requirements have been used as inputs to the model. Moving the animal's requirements for any or all of the resources, and/or changing the concentration of one or more of the resources in the food, results in curves with different positions on the graph, a different total discomfort curve and thus a different prediction for daily food intake. The minimum of the total discomfort curve can be found rapidly using the Solver function in Microsoft Excel ${ }^{\circledR}$ (Redmond, WA, USA).

In reality animals are faced with many more than three resources about which they must make decisions. Amongst these are amino acids, minerals and vitamins and also other dimensions describing 'sensory properties', and yet others describing such things as social factors ${ }^{60}$, effects of weather ${ }^{61}$, and animal-plant interactions including rate of eating and ease of selection between different plants or parts of the same plant ${ }^{62}$. For animals under controlled conditions, individually penned and with access to foods which are formulated to provide adequate concentrations of all but those under examination, the three resources included here are proposed as adequate for a minimal description of food composition and animal requirements. However, poor performance of this three-factor model in the face of changes in protein supply led to the addition of a fourth factor: additional discomfort when the food CP:ME ratio was less than $0.0125 \mathrm{~g} / \mathrm{MJ}(0.25 \mathrm{~kg} \mathrm{CP} / 20 \mathrm{MJ} \mathrm{ME})$, on the grounds that protein deficiency reduces the animal's ability to deal with energy-yielding substrates, leading to an excess of energy. (The limitations of this factor are brought up in suggestions for future development, later.) This fourfactor model is henceforth called the 'Model'.

\section{Model exploration}

Multiple regression 'models' can be tested under conditions similar to those in which it is intended they are to be used, and the one which gives the best predictions identified ${ }^{63}$ but this is not the case with models intended as research tools, designed to explore new concepts. The Model presented in the present paper is clearly in the research model category and close agreement between its predictions and reality is therefore not to be expected. Rather, it should perform reasonably over a much wider range of conditions than regression models. The following sections describe and discuss the ways in which the Model adapts to changes in the food and animal requirements, including two-food situations.

Food quality. The Model was run for foods with different qualities in which $\mathrm{ME}$ content ranged from 6 to $13.5 \mathrm{MJ} \mathrm{ME} / \mathrm{kg}$ in parallel with which $\mathrm{CP}$ was gradually increased from 90 to $200 \mathrm{~g} \mathrm{CP} / \mathrm{kg}$ and NDF decreased progressively from 600 to $100 \mathrm{~g} / \mathrm{kg}$. Fig. 6 shows the predictions of intake plotted against food quality (expressed here as ME/kg) of the food for sheep with standard requirements $(20 \mathrm{MJ} \mathrm{ME} / \mathrm{d}, 0.25 \mathrm{~kg} \mathrm{CP} / \mathrm{d}$ and $0.35 \mathrm{~kg} \mathrm{NDF} / \mathrm{d})$. It can be seen that intake increases with improvements in energy yield up to about $10.5 \mathrm{MJ} \mathrm{ME} / \mathrm{kg}$ $(0.15 \mathrm{~kg} \mathrm{CP}$ and $0.33 \mathrm{~g} \mathrm{NDF} / \mathrm{kg})$ but then decreases with the highest-quality foods. When the ME and CP requirements of the animal are increased by $50 \%$ (but NDF threshold stayed the same), approximating a lactating ewe, the maximum DM intake was predicted to be achieved at an ME content of about $12 \mathrm{MJ} \mathrm{ME} / \mathrm{kg}(0 \cdot 18 \mathrm{~kg} \mathrm{CP}$ and $0.20 \mathrm{~kg} \mathrm{NDF} / \mathrm{kg})$.

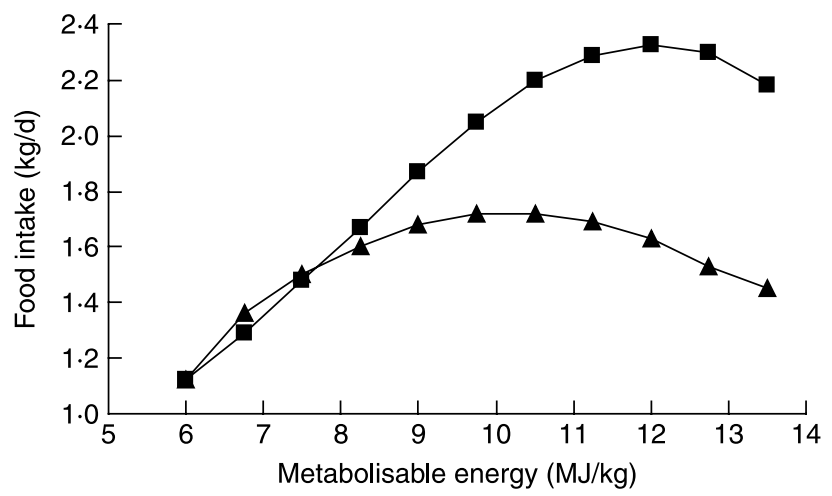

Fig. 6. Predicted intake of foods of a range of nutrient values for a growing sheep $(\diamond)$ and another with nutrient requirements increased by 1.5 times ( $\square$ ) (for details, see Model exploration (Food quality) section). 
An increased productive energy output was thus predicted to increase food intake with diets of high ME content, as commonly observed. The predicted change-over from a positive to a negative relationship is not abrupt, as suggested by Conrad et al. ${ }^{64}$, but, as envisaged by Owen et al. ${ }^{65}$ and observed in practice ${ }^{66,67}$, occurs gradually in a biologically credible manner.

Food protein. The Model was run with the requirements of the standard growing sheep for $\mathrm{CP}$ contents of the forage food increasing from 0 to $0.25 \mathrm{~kg} / \mathrm{kg}$ with $\mathrm{ME}$ and NDF held constant at $10 \mathrm{MJ} / \mathrm{kg}$ and $0.6 \mathrm{~kg} \mathrm{NDF} / \mathrm{kg}$, respectively. The predictions are for intake of the forage to decrease slightly as CP content is increased above the 'optimum' of about $0.15 \mathrm{~kg} \mathrm{CP} / \mathrm{kg}$; below a dietary content of $0.10 \mathrm{~kg} \mathrm{CP} / \mathrm{kg}$, intake falls sharply to reach $0.8 \mathrm{~kg} / \mathrm{d}$ when the diet is protein-free (Fig. 7). With a better-quality food with an $\mathrm{ME}$ of $12 \mathrm{MJ} / \mathrm{kg}$ and NDF of $0.4 \mathrm{~kg} / \mathrm{kg}$, intakes are higher than for the forage, except for the protein-free diet, where intake is again close to $0.8 \mathrm{~kg} / \mathrm{d}$. That very-low-protein diets depress intake as much as they do in the Model is due to the inclusion of the negative feedback of excess ME when there is insufficient protein available to metabolise the energy properly. Clearly the Model behaves unrealistically in that it predicts a significant amount of food to be eaten when the protein content is zero when in fact it is well documented that intake will become zero and death will ensue in animals given diets very low in protein ${ }^{27}$.

Table 1 shows intakes for growing sheep offered diets with different protein contents 57 , together with the predictions of the model without (the three-factor model) and with (the four-factor Model) additional discomfort when the food CP:ME ratio was less than 0.0125 g/MJ. Intake of a low-protein diet is depressed much more with the latter Model than with the former, and is more in line with reality. For this reason the four-factor Model was adopted for the rest of the examples in the present review.

Food protein - supplementation of forage with concentrates. The intake of a forage is almost always reduced when a concentrate supplement is given ${ }^{68}$. The Model was expanded by allowing the daily intake of the forage to

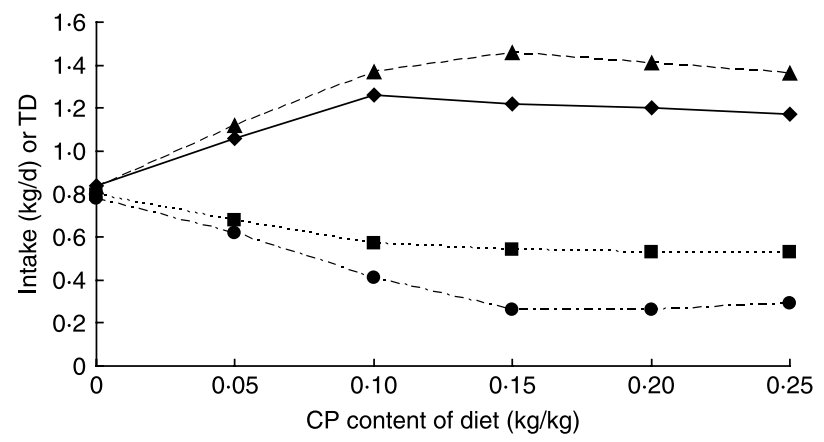

Fig. 7. Predictions by model of food intake and total discomfort (TD) for growing sheep offered foods with different contents of crude protein $(\mathrm{CP})$. Intake $(\bullet, \mathbf{\Delta})$ and TD $(\mathbf{\square}, \bullet)$ of foods providing $10 \mathrm{MJME}$ and $0.6 \mathrm{~kg}$ neutral-detergent fibre $(\mathrm{NDF}) / \mathrm{kg}(\bullet, \mathbf{\square})$ and $12 \mathrm{MJ} \mathrm{ME}$ and $0.4 \mathrm{~kg} \mathrm{NDF} / \mathrm{kg}(\boldsymbol{\Lambda}, \bullet)$.

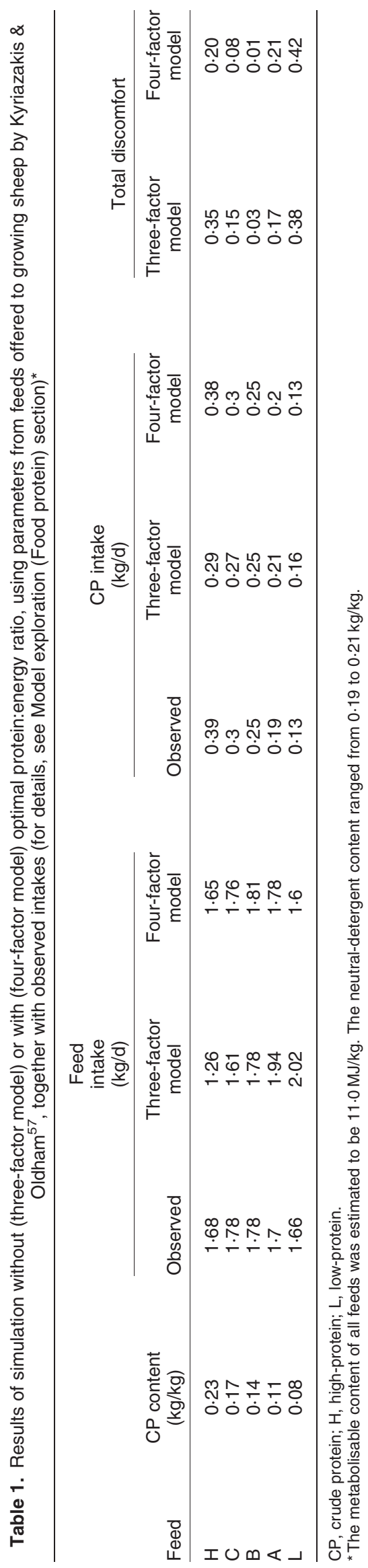


be optimised as before while fixing the intake of the concentrate:

Intake of forage $=$ minimise $\sqrt{\sum_{j=1}^{i} w_{j}\left(\left(c_{j}^{\text {conc }}+c_{j}^{\text {forage }}-o_{j}\right) / o_{j}\right)^{2}}$,

where $c^{\text {conc }}$ is the supply from the fixed intake of supplement and $c^{\text {forage }}$ is the supply from the variable weight of forage eaten.

For the standard growing lamb the predicted intake of forage (10.0 MJ ME; $0.10 \mathrm{~g} \mathrm{CP} ; 600 \mathrm{~g} \mathrm{NDF}$ ) in response to increasing allowances of concentrate $(11.0 \mathrm{ME}, 240 \mathrm{~g} \mathrm{CP}$, $190 \mathrm{~g} \mathrm{NDF} / \mathrm{kg}$, from 0.1 to $1.0 \mathrm{~kg} / \mathrm{d}$ ) decreased at the constant rate (the substitution rate) of $0.69 \mathrm{~kg} / \mathrm{kg}$, which is towards the upper end of the range normally observed; total discomfort decreased as concentrate allowance increased. With a forage $\mathrm{CP}$ content of $50 \mathrm{~g} / \mathrm{kg}$ the substitution rate with concentrate addition up to $0.6 \mathrm{~kg} / \mathrm{d}$ was lower $(0.41 \mathrm{~kg} / \mathrm{kg})$ but reverted to 0.69 above $0.6 \mathrm{~kg}$ supplement $/ \mathrm{d}$. Usually in practice substitution rate increases as the rate of concentrate supplementation increases ${ }^{68}$ and in this simulation it is a protein effect that gives rise to the increase in substitution rate at high levels of supplementation. Another cause of this increase in substitution rate with increasing levels of supplement is the reduction in the rate of fibre digestion with high intakes of starchy concentrates $^{69}$, giving a longer residence time for fibre in the rumen and thus a greater discomfort for any given intake of NDF. No such effect is incorporated in this model.

Choice feeding. Equation 1 is expanded to include $k$ different foods on offer:

Intake $=\operatorname{minimise} \sqrt{\sum_{j=1}^{i} w_{j}\left(\left(\sum_{l=1}^{k} c_{j l}-o_{j}\right) / o_{j}\right)^{2}}$,

where in this case $c_{j}$ is the supply of the $j$ th resource from the current intake of all the $k$ foods and the solution includes the intake of each food as well as the total intake. (It would be possible to combine choice and supplement feeding in the Model, for example, as in research by Lawson et al. ${ }^{37}$, but this has not so far been attempted.) Choice feeding is a particularly good way to investigate animals' abilities to adapt as they learn about the nutritional qualities of foods.

In view of the comprehensive nature of the experiment of Kyriazakis \& Oldham $^{57}$ this has again been used to provide the animal and food specifications for simulations of diet selection. The animal is a sheep with high growth potential and $\mathrm{ME}, \mathrm{CP}$ and $\mathrm{NDF}$ 'requirements' of $20 \mathrm{MJME}$, $250 \mathrm{~g} \mathrm{CP}$ and $350 \mathrm{gNDF} / \mathrm{d}$, as described earlier. The highest-protein feed $(0.23 \mathrm{~kg} / \mathrm{kg})$ was always on offer along with one of the other feeds with protein contents of $0 \cdot 17,0 \cdot 14,0 \cdot 11$ or $0 \cdot 08 \mathrm{~kg} / \mathrm{kg}$.

The Model is programmed to 'experiment' by changing the rates of intake of each food until minimum discomfort is reached, thereby predicting both daily food intake and the proportion of each of the two foods eaten. Table 2 shows the choices made: the observed animals' choice was in a ratio that met the presumed protein requirement, where the protein contents of the two foods allowed this. The Model predicted a 'perfect' dietary protein content and zero 'metabolic discomfort' with choice feeding. However, this was achieved by eating none of the high-protein food whereas the sheep did eat significant amount of that food, calculated to be giving themselves an excess protein intake. The sheep also ate more food than predicted by the Model. Nevertheless, the Model produces output quite similar to the observations of food intake and choice by the growing lambs.

Choice-fed lambs were observed to eat more in total than similar sheep offered single foods ${ }^{57}$ while the Model predicted daily intakes of single- and choice-fed animals to be similar. The Model does not include any explicit means whereby choice feeding might affect total intake in comparison with a balanced single food, and there is no part of the current theory that would provide such a means. However, it is likely in some situations in which no food is balanced when offered by itself, that an appropriate choice will allow a better match between supply of and demand for resources, and total intake could be higher.

\section{Improvements and developments}

The approach adopted earlier appears to provide a model that responds in the appropriate direction when subject to a range of food and animal situations. A number of discrepancies have been highlighted, as might be expected from such a simple representation of a complex situation, and it is likely that future developments will include:

(a) The introduction of additional factors that might contribute to discomfort (rate of eating and grazing time (already used by Forbes ${ }^{54}$ ), ease of prehension, walking distance, heat load, individual amino acids, minerals, vitamins, toxins, fibre type, flavours previously associated

Table 2. Observed and predicted choices made by growing lambs when offered ad libitum access to two feeds with different protein contents, given in Table $1^{57}$

\begin{tabular}{lccccccc}
\hline Feed choice & $\begin{array}{c}\text { Observed } \\
\text { feed intake } \\
(\mathrm{kg} / \mathrm{d})\end{array}$ & $\begin{array}{c}\text { Predicted } \\
\text { feed intake } \\
(\mathrm{kg} / \mathrm{d})\end{array}$ & $\begin{array}{c}\text { Observed } \\
\text { HP:total }\end{array}$ & $\begin{array}{c}\text { Predicted } \\
\text { HP:total }\end{array}$ & $\begin{array}{c}\text { Observed } \\
\text { CP content } \\
(\mathrm{kg} / \mathrm{kg})\end{array}$ & $\begin{array}{c}\text { Predicted } \\
\text { CP content } \\
(\mathrm{kg} / \mathrm{kg})\end{array}$ & $\begin{array}{c}\text { Total discomfort } \\
\text { HL }\end{array}$ \\
\hline HA & 1.93 & 1.81 & 0.34 & 0.38 & 0.13 & 0.14 & 0.00 \\
HB & 1.95 & 1.81 & 0.19 & 0.23 & 0.13 & 0.14 & 0.00 \\
HC & 1.90 & 1.81 & 0.18 & 0.00 & 0.16 & 0.14 & 0.00 \\
\hline
\end{tabular}

$\mathrm{HP}$, high-protein feed; $\mathrm{CP}$, crude protein; HL, high- and low-protein feeds; HA, high-protein feed and feed A; HB, high-protein feed and feed B; HC, highprotein feed and feed $\mathrm{C}$. 
with foods with different properties, social factors); in particular, it should be noted that effects of plant secondary metabolites are increasingly recognised as having beneficial properties at moderate concentrations but being toxic at higher concentrations in plant material ${ }^{70}$.

(b) A more realistic treatment of resource supply, demand and interaction; existing models of ruminant digestion and metabolism could be used as sub-models to provide a more dynamic representation of the animal-food relationship. The Model illustrates one simple approach to incorporating interactions between resources but can be criticised as ME includes energy coming from $\mathrm{CP}$ - they are not independent and will give rise to double-counting errors; the use of 'nonprotein energy' is one possibility although it is not clear how protein would be handled if present in excess of requirements and thus that part of it that is oxidised contributing to energy supply. In addition, the inclusion of the $\mathrm{CP}: \mathrm{ME}$ ratio as a factor violates the claim of additivity unless it can be argued that this is expressing an independent additional feed property not at all captured by $\mathrm{CP}$ and $\mathrm{ME}$.

(c) The functions used to derive discomforts from deviations in resource supply should be explored. Possibly the curve relating discomfort to deviation in resource supply should not be symmetrical about the optimum. It might well be steeper for a nutrient shortfall than for an excess, in relation to requirements, because a deficit reduces fitness while a modest excess can be tolerated, albeit with some increase in discomfort; there might be an optimal comfort range rather than a single optimum point. Additionally, the form of the function might not be quadratic; indeed it is likely to be sigmoid, with a flattening of the 'response' when the 'dose' becomes very high (and unphysiological?). Experimental evidence and/or derivation from the literature of the amount of discomfort arising from a deviation of the supply of each resource from 'requirement' (that assumed to produce zero discomfort) could be used to advance this area.

(d) Although different weightings for different factors affecting intake have been tried out, and arbitrary weightings of 0.33 for $\mathrm{CP}$ and NDF relative to ME have been used ${ }^{35}$, this is hardly justified until we have evidence on which to base such factors.

(e) Very low intake of fibre appears to generate discomfort as ruminants prefer to eat some fibre-containing food even if its nutritive value is low ${ }^{71,72}$; this could be incorporated into the Model to cope with very-low-fibre diets.

(f) Feedbacks from body reserves (insulin, leptin), added to the signals emanating from receptors in the digestive tract and liver to incorporate the long-term aspects of intake control.

\section{Conclusions}

From the simple concept of physical limitation of forage intake that seemed to adequately fit the data up to the $1960 \mathrm{~s}$, through various theories of metabolic control (including those that denied physical factors altogether), we have arrived at a multifactorial hypothesis of the control of feed intake in ruminants: minimal total discomfort. Merely to propose this hypothesis in words is to deny it its full power, which is only seen when the quantitative implementation is developed. It is put forward as a basis for development into a more comprehensive model and, in particular, as a challenge to devise experiments to show areas in which it fails. A failure in this context is not its inability to predict intake to the nearest few percent compared with observed intakes of individual animals, but rather the failure of the broad concept of how different factors are integrated to predict more generally ways in which intake and selection cope with changes in diet, physiology or environment. Agreement between output from a model and reality is never more than circumstantial evidence of the validity of the model. Ultimately, it is only by designing critical experiments to challenge the model that we can gradually build or destroy confidence in its representation of reality. Undoubtedly many of the answers are already available, hidden in the scientific literature, and patient searching is required rather than hasty experimentation. I trust that new generations of scientists will be as stimulated as I have been by these challenges.

While the general hypothesis, that animals learn to minimise deviations between supply and demand for resources, is surely soundly based, the devices adopted here for quantification are speculative. The problem of the model is to find a common currency for the different factors to be incorporated into the model and the method used in the present solution is just one possibility. Nevertheless, even in its present state the hypothesis seems to me to address some of my criticisms of previous modelling exercises.

Because of the complex nature of this quantitative hypothesis it will be difficult to validate and it remains to be seen how useful the approach will be to assisting in the practical management and ration formulation for farm animals. Perhaps ultimately it will be found that either the approach is wrong in principle, or that its parameters (weightings) can never be estimated. In the meantime if it serves to stimulate thought and experimentation leading to advances in our understanding then I will be well satisfied.

\section{Acknowledgements}

I am grateful to Gerry Emmans for stimulating discussions and positively critical comments on an early draft of the present review; to Fred Provenza for his support from afar and Brian Sleeman for being so interested in this biological problem from a mathematician's point of view.

\section{References}

1. Gallouin F \& Le Magnen J (1987) Évolution historique des concepts de faim, satiété et appétits (Historical development of the concepts of hunger, satiety and appetite). Réprod Nutr Dév 27, 109-128.

2. Balch CC \& Campling RC (1962) Regulation of voluntary food intake in ruminants. Nutr Abstr Rev 32, 669-686.

3. Booth DA, Toates FM \& Platt SV (1976) Control systems for hunger and its implications in animals and man. In Hunger; Basic Mechanisms and Clinical Implications, pp. 127-144 [D Novin, editor]. New York: Raven Press.

4. Wirtshafter D \& Davis JD (1977) Set points, settling points, and the control of body weight. Physiol Behav 19, 75-78. 
5. Forbes JM (1977) Development of a model of voluntary food intake and energy balance in lactating cows. Anim Prod 24, 203-214.

6. Forbes JM (1977) Interrelationships between physical and metabolic control of voluntary food intake in fattening, pregnant and lactating mature sheep: a model. Anim Prod 24, 91-101.

7. Forbes JM (1980) A model of the short-term control of feeding in the ruminant: effects of changing animal or feed characteristics. Appetite 1, 21-41.

8. Poppi DP, Gill M \& France J (1994) Integration of theories of intake regulation in growing ruminants. $J$ Theor Biol 167, 129-145.

9 Fisher DS (1996) Mathematical integration of distension and chemostatic feedbacks for regulation of ruminant intake in diets with varied dietary protein. J Anim Sci 74, 3076-3081.

10. Forbes JM (1995) Physical limitations of feed intake in ruminants and its interactions with other factors affecting food intake. In Ruminant Physiology: Digestion, Metabolism, Growth and Reproduction, pp. 217-232 [W von Engelhardt, S Leonhard-Marek, G Breves and D Giesecke, editors]. Stuttgart: Ferdinand Enke Verlag.

11. Blaxter KL \& Wilson RS (1963) The assessment of a crop husbandry technique in terms of animal production. Anim Prod 5, 27-42.

12. Dinius DA \& Baumgardt BR (1970) Regulation of food intake in ruminants. 6. Influence of caloric density of pelletted rations. J Dairy Sci 53, 311-316.

13. Blaxter KL (1962) The Energy Metabolism of Ruminants, p. 282. London: Hutchinson.

14. Baumgardt BR (1970) Regulation of feed intake and energy balance. In Physiology of Digestion and Metabolism in the Ruminant, pp. 235-253 [AT Phillipson, editor]. Newcastle upon Tyne: Oriel Press.

15. Forbes JM (2005) Voluntary feed intake and diet selection. In Quantitative Aspects of Ruminant Digestion and Metabolism, pp. 607-625 [J Dijkstra, JM Forbes and J France, editors]. Wallingford, Oxfordshire: CABI Publishing.

16. Tolkamp BJ \& Ketelaars JJMH (1992) Toward a new theory of feed intake regulation in ruminants. 2. Costs and benefits of feed consumption: an optimization approach. Livest Prod Sci 30, 297-317.

17. Pittroff W \& Kothmann MM (1999) Regulation of intake and diet selection by herbivores. In Nutritional Ecology af Herbivores, pp. 366-422 [HG Jung and GC Fahey, editors]. Savoy, IL: American Society of Animal Science.

18. Baile CA \& Forbes JM (1974) Control of feed intake and regulation of energy balance in ruminants. Physiol Rev 54, 160-214.

19. Leek BF (1986) Sensory receptors in the ruminant alimentary tract. In Control of Digestion and Metabolism in Ruminants, p. 317 [LP Milligan, WL Grovum and A Dobson, editors]. New Jersey: Prentice Hall.

20. Carter RR \& Grovum WL (1990) A review of the physiological significance of hypertonic body fluids on feed intake and ruminal function: salivation, motility and microbes. J Anim Sci 68, 2811-2832.

21. Engku Azahan EA \& Forbes JM (1992) The effects of intraruminal infusions of sodium salts on the selection of hay and concentrate foods by sheep. Appetite 18, 143-154.

22. Forbes JM, Mbanya JN \& Anil MH (1992) Comparisons of the effects of intraruminal infusions of sodium acetate and sodium chloride on silage intake by lactating cows. Appetite 19, 293-301.

23. Ternouth JH \& Beattie AW (1971) Studies of the food intake of sheep at a single meal. Br J Nutr 25, 153-164.
24. Barrio JP, Bapat ST \& Forbes JM (1991) The effect of drinking water on food-intake responses to manipulations of rumen osmolality in sheep. Proc Nutr Soc 50, 98A.

25. Anil MH \& Forbes JM (1987) Neural control and sensory functions of the liver. Proc Nutr Soc 46, 125-133.

26. Forbes JM (1988) Metabolic aspects of the regulation of voluntary food intake and appetite. Nutr Res Rev 1, 145-168.

27. Forbes JM (1995) Voluntary Food Intake and Diet Selection in Farm Animals, 1st ed. Wallingford, Oxfordshire: CAB International.

28. Oldham JD, Emmans G \& Friggens N (1998) Development of predictive systems to relate animal and feed characteristics to amounts and patterns of forage, and total food, intake by cows. In Optimisation of Forage Quality and Intake by Ruminants, Report to MAFF on DSO4 [M Gill, editor]. Chatham: Natural Resources International Ltd.

29. Stephens DW \& Krebs JR (1986) Foraging Theory. Princeton, NJ: Princeton University Press.

30. Thornley JHM, Parsons AJ, Newman J \& Penning PD (1994) A cost-benefit model of grazing intake and diet selection in a two-species temperate grassland sward. Funct Ecol 8, 5-16.

31. Ketelaars JJMH \& Tolkamp BJ (1992) Toward a new theory of feed intake regulation in ruminants. 3. Optimum feed intake: in search of a physiological background. Lives Prod Sci 31, 235-258.

32. Agricultural Research Council (1980) The Nutrient Requirements of Ruminant Livestock. Farnham Royal, UK: Commonwealth Agricultural Bureaux.

33. Emmans GC \& Kyriazakis I (1995) The idea of optimisation in animals: uses and dangers. Livest Prod Sci 44, 189-197.

34. Pittroff W \& Kothmann MM (2001) Quantitative prediction of feed intake in ruminants. III. Comparative example calculations and discussion. Livest Prod Sci 71, 171-181.

35. Forbes JM \& Provenza FD (2000) Integration of learning and metabolic signals into a theory of dietary choice and food intake. In Ruminant Physiology: Digestion, Metabolism, Growth and Reproduction, pp. 3-19 [PB Cronje, editor]. Wallingford, Oxfordshire: CAB International.

36. Tolkamp BJ, Kyriazakis I, Oldham JD, Lewis M, Dewhurst RJ \& Newbold JR (1998) Diet choice by dairy cows. 2. Selection for metabolizable protein or for ruminally degradable protein? J Dairy Sci 81, 2670-2680.

37. Lawson RE, Redfern EJ \& Forbes JM (2000) Choices by lactating cows between concentrates high and low in digestible undegraded protein. Anim Sci 70, 515-525.

38. Arsenos G \& Kyriazakis I (1999) The continuum between preferences and aversions for flavoured foods in sheep conditioned by administration of casein doses. Anim Sci $\mathbf{6 8}$, 605-616.

39. Raubenheimer D \& Simpson SJ (1997) Integrative models of nutrient balancing: application to insects and vertebrates. Nutr Res Rev 10, 151-179.

40. Dutoit JT, Provenza FD \& Nastis A (1991) Conditioned tasteaversions - how sick must a ruminant get before it learns about toxicity in foods? Appl Anim Behav Sci 30, 35-46.

41. Villalba JJ \& Provenza FD (1997) Preference for flavored wheat straw by lambs conditioned with intraruminal infusions of acetate and propionate. J Anim Sci 75, 2905-2914.

42. Forbes JM \& Barrio JP (1992) Abdominal chemo- and mechanosensitivity in ruminants and its role in the control of food intake. Exp Physiol 77, 27-50.

43. Forbes JM (1996) Integration of regulatory signals controlling forage intake in ruminants. J Anim Sci 74, 3029-3035.

44. Forbes JM (1980) Physiological aspects of the control of food intake. Ann Zootech 29, 189-196. 
45. Adams G \& Forbes JM (1981) Additivity of effects of ruminal acetate and either portal propionate or rumen distension on food intake in sheep. Proc Nutr Soc 40, 44A.

46. Mbanya JN, Anil MH \& Forbes JM (1993) The voluntary intake of hay and silage by lactating cows in response to ruminal infusion of acetate or propionate, or both, with and without distension of the rumen by a balloon. Br J Nutr 69, $713-720$

47. Jessen C (1981) Independent clamps of peripheral and central temperatures and their effects on heat production in the goat. J Physiol 311, 11-22.

48. Forbes JM (1986) The Voluntary Food Intake of Farm Animals. London: Butterworths.

49. Anil MH, Mbanya JN, Symonds HW \& Forbes JM (1993) Responses to the voluntary intake of hay or silage by lactating cows to intraruminal infusions of sodium acetate or sodium propionate, the tonicity of rumen fluid or rumen distension. Br J Nutr 69, 699-712.

50. Tulloh NM (1966) Physical studies of the alimentary tract of grazing cattle IV. Dimensions of the tract in lactating and non-lactating cows. N Z J Agric Res 9, 999-1008.

51. Egan AR (1970) Nutritional status and intake regulation in sheep. 6. Evidence for variation in setting of an intake regulatory mechanism relating to the digesta content of the reticulorumen. Aust J Agric Res 21, 735-746.

52. Villalba JJ \& Provenza FD (2000) Roles of novelty, generalization, and postingestive feedback in the recognition of foods by lambs. J Anim Sci 78, 3060-3069.

53. Provenza FD (1996) Acquired aversions as the basis for varied diets of ruminants foraging on rangelands. J Anim Sci 74, 2010-2020.

54. Forbes JM (2001) Consequences of feeding for future feeding. Comp Biochem Physiol 128, 461-468.

55. Forbes JM (2003) The multifactorial nature of food intake control. J Anim Sci 81, E139-E144.

56. Yeates MP, Tolkamp BJ \& Kyriazakis I (2002) The relationship between meal composition and long-term diet choice. J Anim Sci 80, 3165-3178.

57. Kyriazakis I \& Oldham JD (1993) Diet selection in sheep: the ability of growing lambs to select a diet that meets their crude protein (nitrogen $\times 6.25$ ) requirements. $\mathrm{Br} J \mathrm{Nutr}$ 69, 617-629.

58. Forbes JM (1999) Minimal total discomfort as a concept for the control of food intake and selection. Appetite 33, 371.
59. Van Soest PJ (1994) Nutritional Ecology of the Ruminant, 2nd ed. Ithaca, NY: Cornell University Press.

60. Sibbald AM, Smith DJF \& Hooper RJ (2000) Individual differences in sociability and their consequences for foraging in sheep. Proc Br Soc Anim Sci 2000, 129.

61. Riggs R, Urness PJ \& Gonzalez KA (1990) Effects of domestic goats on deer wintering in Utah oakbrush. $J$ Range Manag 43, 229-234.

62. Illius A, Clark D \& Hodgson J (1992) Discrimination and patch choice by sheep grazing grass-clover swards. J Anim Ecol 61, 183-194.

63. Neal HD, Thomas C \& Cobby JM (1984) Comparison of equations for predicting voluntary intake by dairy cows. $J$ Agric Sci 103, 1-10.

64. Conrad HR, Pratt AD \& Hibbs JW (1964) Regulation of feed intake in dairy cows. 1. Change in importance of physical and physiological factors with increasing digestibility. J Dairy Sci 47, 54-62.

65. Owen JB, Davies DAR \& Ridgman WJ (1969) The control of voluntary food intake in ruminants. Anim Prod 11, $511-520$.

66. Bines JA (1979) Voluntary food intake. In Feeding Strategy for the High Yielding Dairy Cow, pp. 23-48 [WH Broster and H Swan, editors]. London: Granada.

67. National Research Council (1987) Predicting Feed Intake of Food-Producing Animals, p. 57. Washington, DC: National Academic Press.

68. Faverdin P, Dulphy JP, Coulon JB, Verite R, Garel JP, Rouel J \& Marquis B (1991) Substitution of roughage by concentrates for dairy cows. Livest Prod Sci 27, 137-156.

69. Lamb CS \& Eadie J (1979) The effect of barley supplements on the voluntary intake and digestion of low quality roughages by sheep. J Agric Sci 92, 235-241.

70. Provenza FD, Villalba JJ, Dziba LE, Atwood SB \& Banner RE (2003) Linking herbivore experience, varied diets, and plant biochemical diversity. Small Rumin Res 49, 257-274.

71. Cooper SDB, Kyriazakis I \& Oldham JD (1996) The effects of physical form of feed, carbohydrate source, and inclusion of sodium-bicarbonate on the diet selections of sheep. J Anim Sci 74, 1240-1251.

72. Campion DP \& Leek BF (1997) Investigation of a "fibre appetite" in sheep fed a "long fibre-free" diet. Appl Anim Behav Sci 52, 79-86. 